\title{
Intermolecular Interactions of Anti-Tuberculosis Drugs with Different Solvents: A Review
}

\author{
Mamata Pradhan 1(i), Binita Nanda ${ }^{2(\mathbb{D})}$, Prativa $\operatorname{Kar}^{1}{ }^{10}$, Braja B. Nanda ${ }^{3, *(\mathbb{C})}$ \\ 1 Department of Chemistry, GIET University, Gunupur, Odisha, India;mamata.pradhan91@gmail.com (M.P.); \\ 2 Department of Chemistry, ITER, Sikshya' O'Anusandhan (Deemed to be University), Bhubaneswar, India; \\ binita.driems@gmail.com (B.N.); \\ 3 P.G. Department of Chemistry, Vikram Deb Autonomous College, Jeypore-764001, Odisha, India; \\ bbnanda.driems@gmail.com (B.B.N.); \\ * Correspondence:bbnanda.driems@gmail.com;
}

Scopus Author ID 8431581400

Received: 11.02.2021; Revised: 10.04.2021; Accepted: 14.04.2021; Published: 26.04.2021

\begin{abstract}
Drugs' action in the human body is called pharmacodynamics. A drug is any chemical substance that causes a change in an organism's psychology. Today's world is suffering from a common disease called tuberculosis (TB). TB is a common bacterial infection caused by mycobacterium tuberculosis. So, to fight against such type of infection, the study of ion-solvent interaction plays a significant role. To understand molecular interactions, solution properties of anti-TB drugs with different solvents at different temperatures, various physicochemical properties such as volumetric properties, thermo-acoustical properties, viscometric and conductometric properties etc., can be studied. In the present review, the emphasis has been given to the volumetric and ultrasonic properties to study anti-TB drugs' inter-molecular interactions in different solvents.
\end{abstract}

Keywords: physicochemical properties;anti-tuberculosis drugs; ultrasonic velocity; isoniazid.

(C) 2021 by the authors. This article is an open-access article distributed under the terms and conditions of the Creative Commons Attribution (CC BY) license (https://creativecommons.org/licenses/by/4.0/).

\section{Introduction}

In 1966, WHO defined drugs as any chemical substance related to pharmacology science, which is used to explore the recipient's physiological system [1-5]. Drugs' impact and action in the human body is commonly called pharmacodynamics [6-9]. Drugs may be soft and hard based on their uses. Soft drugs such as marijuana, sleeping pills, and valium are also called narcotics drugs, are less addictive and less harmful to the body. On the other hand, hard drugs like heroin, codeine, morphine are those which get addicted once used and are harmful to the body. Otherwise, these are also called non-narcotics drugs. Drugs can be utilized in two different ways, either legal or illegal way. A legal drug is that which is used for the illness and disease under prescription by the doctors. In contrast, illegal or illicit drugs are not prescribed by doctors and are used illegally. Drugs have a low molecular mass of about 100-500amu, and when they interact with bimolecular, they initiate physiological or biological responses.

\subsection{About anti-tuberculosis (TB).}

Mycobacterium tuberculosis bacteria are mainly responsible for $\mathrm{TB}$, which affects mainly the lungs. TB can be spread from person to person through the air by respiratory droplets, cough, sneezing, by saliva like sharing drinks or kissing. Active infection occurs more often in people who have HIV/AIDS or smoke. 


\subsection{Types of anti-tuberculosis drugs.}

There are two types of anti-tuberculosis drugs such as first-line drugs and second-line drugs. First-line anti-tuberculosis drugs are isoniazid (INH), pyrazinamide (PZA), ethambutol (IEMB), streptomycin (SM), rifampicin (RIF), etc. Similarly, the other type of Anti Tuberculosis drugs are second-line drugs, and examples are levofloxacin(LEV), moxifloxacin(MOX), ofloxacin (OFX), and ciprofloxacin (CIP), etc. Some first-line antituberculosis drugs, their functions, and structures are given in Table 1.

Table 1. Some first-line anti-TB drugs with their functions

\begin{tabular}{|c|c|}
\hline Drug Structure & Drug Functions \\
\hline Isoniazid & $\begin{array}{l}\text { This is the most important drug used with other medications to treat active tuberculosis } \\
\text { (TB) infections. Isoniazid was synthesized in the year 1912. Isoniazid plays an important } \\
\text { role in the therapeutic uses against TB [10]. Some of these drugs' side effects are feeling } \\
\text { tired, undesired to eat food, nausea, vomiting, and the liver, etc. }\end{array}$ \\
\hline Rifampicin (RIF) & $\begin{array}{l}\text { This is an antibiotic medication used to prevent and treat tuberculosis and other } \\
\text { infections. It does not work for viral infections like the common cold, flu, etc. } \\
\text { Rifampicin should be taken on an empty stomach. This is because our body absorbs } \\
\text { less rifampicin if taken simultaneously as food, which means it is less effective. The side } \\
\text { effect of .this antibiotic includes the formation of a pinkish/orange colored urine, saliva, } \\
\text { and sweat[11] }\end{array}$ \\
\hline Ethambutol (EMB) & $\begin{array}{l}\text { Ethambutol or myambutolis used with other medicines like rifampicin, pyrazinamide } \\
\text { and isoniazid to cure TB. It is only used for the treatment of bacterial infections and can't } \\
\text { be used for general flu. The common side effects of ethambutol are headache, nausea, } \\
\text { joint pain, vomiting, and dizziness, and it may also cause liver damage[11] }\end{array}$ \\
\hline Pyrazinamide (PZA) & $\begin{array}{l}\text { Pyrazinamide is a type of medication that kills or stops the growth of certain bacteria } \\
\text { that causes TB. It is highly specific in nature and can be used only against } \\
\text { mycobacterium tuberculosis. It is generally used for the treatment of latent tuberculosis. } \\
\text { Overdoses can lead to nausea and a loss of appetite, rashes, fever aches, and joint pain. } \\
\text { It is usually taken for the first two to three months of treatment[12] }\end{array}$ \\
\hline Streptomycin (SM) & $\begin{array}{l}\text { Streptomycin is a type of drug used to treat bacterial infections like tuberculosis, } \\
\text { endocarditis, brucellosis, etc. This is used with other medications for the treatment of } \\
\text { TB. This drug belongs to the class known as aminoglycoside antibiotics[13]. }\end{array}$ \\
\hline
\end{tabular}

\section{Intermolecular Interactions of Anti TB Drugs with Different Solvents}

When drugs are taken with or without foods, they can interact with the body's liquids. During formulations, many types of solvents are also be used. Knowing the effectiveness of the solvent or the drug delivery in the body, the intermolecular interactions of drugs give the solvents usefulness. The better the interaction, the better the drug action. Therefore, here we have analyzed some anti-TB drugs' interactions with different solvents from density, viscosity, conductance, and ultrasonic viscosity data [14-18]. The detailed intermolecular interactions are described in Scheme 1. 


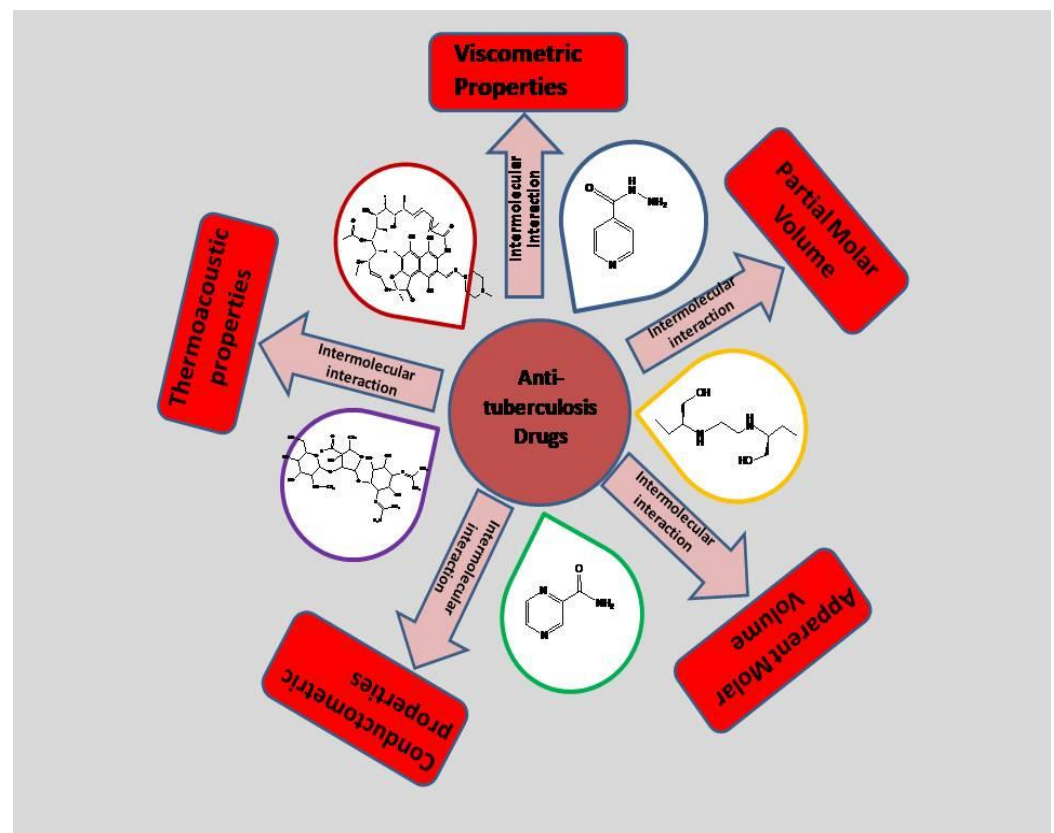

Scheme 1. Schematic representation of intermolecular interactions of different anti-tuberculosis drugs.

Water exists in a dynamic equilibrium between the three-dimensional hydrogen-bonded cluster and denser monomer. As shown below:

$$
\left(\mathrm{H}_{2} \mathrm{O}\right)_{\mathrm{c}} \rightleftharpoons\left(\mathrm{H}_{2} \mathrm{O}\right)_{\mathrm{d}}
$$

where $\mathrm{c}$ is the cluster medium and $\mathrm{d}$ is the denser medium. When drugs are mixed with water, they can break or make the structure. The ions are surrounded by some water molecules and make a spherical structure around them (Scheme 2).

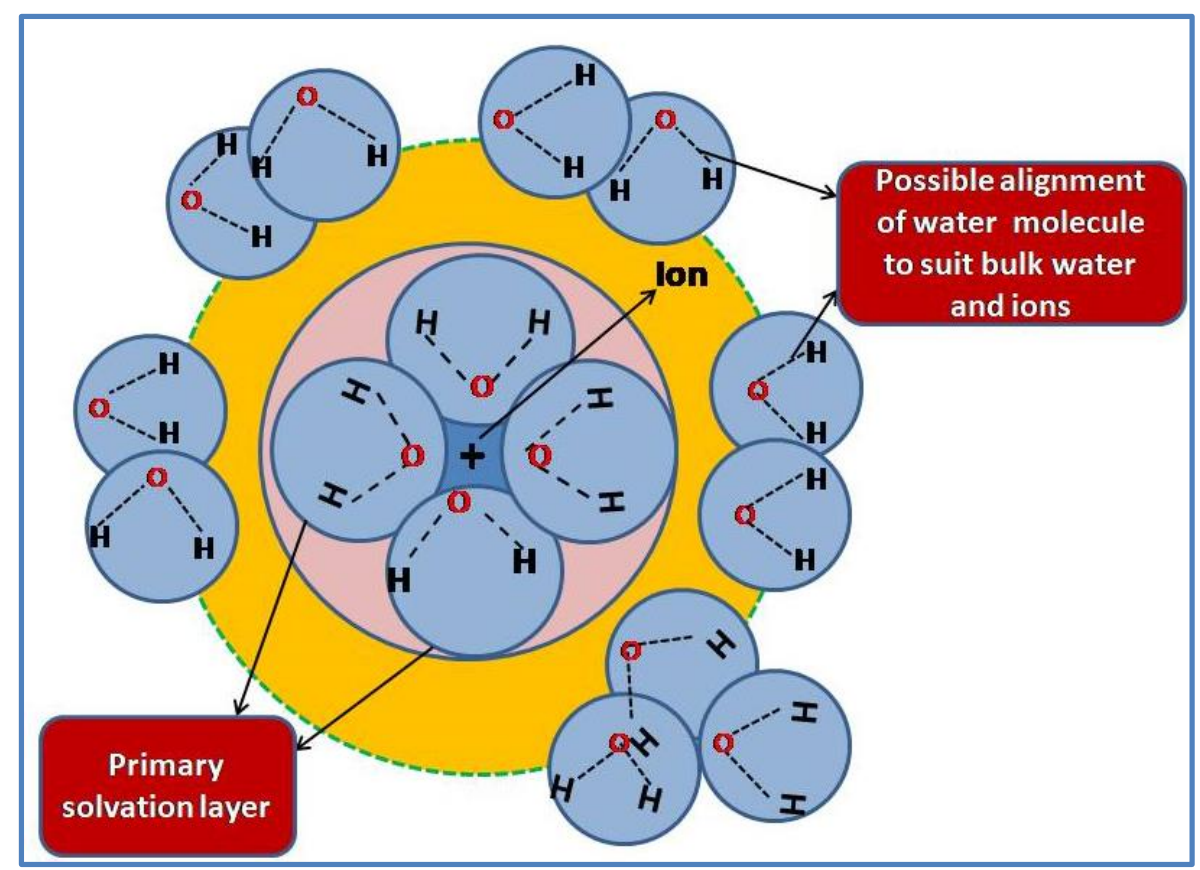

Scheme 2. Schematic diagram to indicate that in the (hatched) region between the primary solvated ion and bulk water, the in-between water molecules must compromise between an orientation that suits the ion (oxygen facing ion) and orientation that suits the bulk water (hydrogen facing ion).

Drugs with high charge density are called structure breakers, and those with low charge density are called structure makers. Typically, drugs with better intermolecular interaction are better for use with more efficiency. The physicochemical properties of drugs consist of physical 
and chemical interactions. Physical interactions of drugs are responsible for their action, and drugs react extracellular according to a simple chemical reaction. The various physicochemical properties of drugs are solubility, partition coefficient, dissociation constant, hydrogen bonding, ionization of drugs, redox potential, complexation, etc. All these properties play an important role in the pharmacology effect of drugs. The solute-solvent interactions cannot be studied directly as salts, carbohydrates, and other co-solutes influence them. So solute-solvent interactions are significant to study drug actions and their mechanism within the body [19-24]. The volumetric and ultrasonic studies are very accurate methods to evaluate the solute-solvent interactions of solutions. In the present study, the intermolecular interactions of some anti TB drugs with different solvents have been discussed using volumetric and ultrasonic methods.

\subsection{Apparent molar volume.}

Apparent molar volume is defined as the difference between the volumes of the solution to the pure solvent volume per mole of solute [25-26]. A reliable and convenient method for understanding ion-ion, ion-solvent, and solvent-solvent interactions is the volumetric characterization of solutions. According to the solvation theory, ions are believed to be surrounded by solvent molecules forming solvation spheres around them. The water molecules are held to the ions by hydrogen bonds and ion-dipole attractions. The solvent molecules in the ions' vicinity are influenced by the electrostatic force exerted by the ions. Thus, there is a difference in volume between electro-stricted solvent molecules in the solvation shells and those in bulk solution. Values of apparent molar volume $V_{\phi}$ are calculated by using the density data as follows [27].

$$
V_{\phi}=\frac{M_{2}}{\rho}+\frac{\left(\rho^{0}-\rho\right)}{m_{A} \rho \rho^{0}}
$$

where, $m_{A} / \mathrm{mol} \mathrm{kg}^{-1}$ is the molality, $M_{2} / \mathrm{kg} \mathrm{mol}^{-1}$ is the molar mass of the drug, $\rho / \mathrm{kg} \mathrm{m}^{-3}$ and $\rho^{0} / \mathrm{kg} \mathrm{m}^{-3}$ are the density of the solution and pure solvent, respectively. The limiting apparent molar volume or partial molar volume $V_{\phi}^{0}$ can be calculated by the Masson equation [28].

$$
V_{\phi}=V_{\phi}^{0}+S_{v}^{e x} \sqrt{m_{A}}
$$

The $V_{\phi}^{0}$ values can be obtained from the plot of $V_{\phi} \mathrm{vs} \cdot \sqrt{m_{A}}$. The coefficients $S_{v}^{e x}$ of equation indicates the solute-solute interaction and the positive values of $V_{\phi}^{0}$ shows the existence of ion - solvent. The limiting apparent molar expansibility, $E_{\phi}^{0} / \mathrm{m}^{3} \mathrm{~mol}^{-1} \mathrm{~K}^{-1}$ is a very important parameter to study interionic interactions established in different solutions, which can be calculated by, $E_{\phi}^{0}=\left(\partial V_{\phi}^{0} / \partial \mathrm{T}\right)_{\mathrm{p}}=\mathrm{a}_{1}+2 \mathrm{a}_{2} \mathrm{~T}$. Further, the structure promoting and structure breaking capacity of a solute in the mixed solutions is determined with the help of the Hepler equation [29] by knowing the sign of $\left(\partial^{2} V_{\phi}^{0} / \partial \mathrm{T}^{2}\right)_{\mathrm{p}}$ or $\left(\partial E_{\phi}^{0} / \partial \mathrm{T}\right)$. The structure making nature of solute in solutions is due to the small negative or positive value of $\left(\partial E_{\phi}^{0} / \partial \mathrm{T}\right)_{\mathrm{p}}$ and structure breaking is due to the large negative value of $\left(\partial E_{\phi}^{0} / \partial \mathrm{T}\right)_{\mathrm{P}}$.

\subsection{Apparent molar isentropic compressibility.}

The apparent molar isentropic compressibility, $K_{\phi, S} / \mathrm{m}^{5}(\mathrm{~mol} \mathrm{~N})^{-1}$ can be computed as follows; 


$$
K_{\phi, S}=\frac{M_{2} \kappa_{S}}{\rho}+\frac{\left(\kappa_{S} \rho_{0}-\kappa_{S}^{0} \rho\right)}{m_{A} \rho \rho_{0}}
$$

where molecular mass is denoted as $M_{2} / \mathrm{kg} \mathrm{mol}^{-1}$, molality is $m_{A} / \mathrm{mol}_{\mathrm{kg}} \mathrm{kg}^{-1}$ of drugs in solution, the densities of the solution and pure solvent are denoted as $\rho / \mathrm{kg} \mathrm{m}^{-3}$ and $\rho^{0} / \mathrm{kg} \mathrm{m}^{-3}$ respectively. The isentropic compressibility of pure solvent and the solutions are given by the formula $\kappa_{s}^{0} / \mathrm{m}^{2} \cdot \mathrm{N}^{-1}$ and $\kappa_{S} / \mathrm{m}^{2} \cdot \mathrm{N}^{-1}$ respectively. Again to determine the isentropic compressibility, the experimentally determined values of ultrasonic speed, $u$ and density, $\rho$ can be used (by using Laplace's equation, $\kappa_{s}=\frac{1}{\rho u^{2}}$ ). The limiting apparent molar isentropic compressibility, $K_{\phi, S}^{0}$, can be determined by the Masson-type equation: $K_{\phi, S}=K_{\phi, S}^{0}+S_{k}^{e x} \sqrt{m}$. From the values of, $K_{\phi, S}^{0}$ and $S_{k}^{e x}$ one can determine ion-solvent interactions in the given solutions [30]. Further, the negative value of $K_{\phi, S}$, shows that the water particles in the bulk region are less compact than the water particles present near the ions. This is owing to the strong ion-solvent attractions and the predominance of hydrophilic-ionic group interactions in solutions. The positive value of $K_{\phi, S}$ indicates the presence of weak interactions between the solute and solvents.

\section{Results and Discussions}

Ankita et al. studied the intermolecular interactions of isoniazid with water and mixed solvents such as aqueous D-xylose /D-arabinose, glucose, and sucrose at different temperatures using volumetric, acoustical, and viscometric properties [30, 31]. Density increases with an increase in concentration and decreases with an increase in the solutions' temperature. Apparent molar volume, $V_{\phi}$ values were positive, indicating strong solute-solvent interactions between isoniazid and aqueous D-xylose, D-arabinose, glucose, and fructose solutions. The increasing values of ultrasonic velocity with increased temperature in all the solutions are due tothe association between solute and solvent. The positive values of transfer volume and transfer compressibility reflect the strong solute-solvent interaction and ion-hydrophilic interaction between INH+D-xylose/D-arabinose/ glucose/fructose. The positive value of the Heplers constant $\left(\partial E_{\phi}^{0} / / \partial \mathrm{T}\right)$ indicates that isoniazid acts as a structure maker in the said solutions. Latha Malladi et al. have studied thermodynamics properties of isoniazid in aqueous solutions of $\mathrm{NaCl} / \mathrm{KCl}$ ) [32]. Their experiment found that the values of density decrease with an increase in the temperature at a particular concentration. Speed of sound increases with the increase of temperature with an increase in the concentration of $\mathrm{NaCl}$ or $\mathrm{KCl}$. Apparent molar volume increase with the increase of molality of isoniazid (INH) at a particular concentration. From these data, they found solute-solvent interactions of ( $\mathrm{INH}+$ water+KCl) system are stronger than $(\mathrm{INH}+$ water $+\mathrm{NaCl})$ system. Further, the isentropic compressibility $\left(\kappa_{s}\right)$ decreases as increases of molality for every concentration and different temperature. Positive transfer properties value also indicates the presence of hydrophilic-ionic interaction. The negative value of limiting compressibility, $K_{\phi, S}^{0}$ study reveals the strong, attractive interaction between isoniazid and water.

Jyoti Gupta et al. [33] have checked the interaction of Isoniazid-amino acid (glycine, 1alanine, l-valine, and l-isoleucine) from different parameters such as the Falkenhagen coefficient $\left(V_{\phi}^{0}\right)$, transfer properties $\left(V_{\phi}\right)$, Jones-Dole coefficient, the free energy of activation per mole of solvent, the free energy of activation per mole of the solute, and $\mathrm{dB} / \mathrm{dT}$. In all the 
four amino acids the $V_{\phi}$ values increase with the increase in the concentration of isoniazid. Values of $V_{\phi}^{0}$ for glycine/ l-alanine/l - valine/l-isoleucine in aqueous-isoniazid are larger than those in pure water, i.e., transfer values are positive. The values of $K_{\phi, S}^{0}$ are negative for glycine/l-alanine/lvaline/l-isoleucine in water and aqueous-isoniazid solutions, indicating the existence of strong solute-solvent interactions and weak solute-solute interactions in these systems. The values of $K_{\phi, S}^{0}$ increase with the increase in temperature, indicating the release of more water molecules from the loose secondary solvation layer of amino acid zwitterions into the bulk, so solutions become more compressible.

Jyoti Gupta et al. [34] have also studied streptomycin sulfate interaction in aqueous Lasparagine and L-glutamine. The data shows that the values of density and viscosity decrease with an increase in temperature, whereas values of ultrasonic velocity increase with an increase in both temperature and concentration. The positive value of partial molar volume, $V_{\phi}^{0}$ shows the presence of strong solute-solvent interactions, which increase with the increase of concentration. Moreover, the partial molar volume for streptomycin sulfate in L-asparagine /Lglutamine and water is very large as compared to streptomycin sulfate in water. This proves the presence of hydrophilic-ionic group interactions and the said drug's structure-making property in aqueous L-asparagine /L-glutamine solvents.

Ion-solvent interaction of streptomycin sulfate with L-ascorbic acid and citric acid has been studied by Sharma et al. [35]. The study shows that both the values of density and ultrasonic velocity increase with increases in concentration and decrease with temperature increases. The positive limiting apparent molar expansibility $\left(E_{\phi}^{0}\right)$ values indicate ionhydrophilic and hydrophilic-hydrophilic interactions between solute-solvent. The Hepler's constant $\left(\partial E_{\phi}^{0} / \partial \mathrm{T}\right)$ is found to be positive, indicating the presence of structure-making nature of the solute.

Shiraz A. Markarian et al.[36] have observed UV-VIS, FTIR, and densitometry data of isoniazid (INH) in diethylsulfoxide (DESO) at different temperatures. As expected, with an increase in temperature, the density of solutions decreases. The apparent molar volume $V_{\phi}$ increases with the increase of concentration and almost constant after very high concentration [37]. They also found limiting apparent molar volume decrease with the increase of temperature. This negative value of $V_{\phi}^{0}$ indicates the presence of strong solute-solute interactions as compared to solute-solvent interaction. They also evaluated $S_{\mathrm{v}}$ 's positive value, which proves the strong solute-solute interaction in the INH+DESO system.[38,39]. From UVVIS and FTIR study, the complex formation ability and hydrogen bonding presence between INH and Sulphoxide molecule was confirmed [40].

C. Nadejde and et al. have studied solute-solvent interactions of the ternary solution of rifampicin-water-alcohol in terms of their spectral data. They observed that water and ethanol exhibited the most significant spectral shifts than the non-polar solvents with rifampicin. From their observation, they found the interaction shows $\pi-\pi *$ electronic transition [41]. While passing through polar to non-polar medium, they observed bathochromic shift and confirmed intermolecular hydrogen bonds and four metastable rifampicin conformers [42].

S. D. Deosarkar et al. [43] have evaluated drug-amino acid interaction by observing their density, viscosity, and refractometric data at $298.15 \mathrm{~K}$. From their experiment, they found the presence of electrostatic and hydrophilic or ionic interactions between solute-solute, solute- 
solvent, and solvent-solvent molecules. Positive values of apparent molar volume and partial molar volume of glycine indicated the presence of strong solute-solvent interactions.

The solution properties of isoniazid (INH) in aqueous and dimethylsulfoxide (DMSO) were studied by S.A. Markarian et al. In their research, they observed that both density and viscosity increase with the increase of concentration and decreases with the increase of temperature. Apparent molar volume increases with the increase of concentration [44]. Negative $V_{\phi}$ indicate strong solute-solute interaction as compared to solute-solvent interaction. This negative value was obtained for the solution containing non-electrolyte [37]. They also observed spectral properties of INH+water and INH+DMSO. From the FT-IR study, the hydrogen bond between INH+DMSO molecule was confirmed, and from UV-VIS absorption spectra $\pi$ - the electronic transition was observed due to the interaction between $\mathrm{NH}_{2}$ and the sulphoxide group.

\section{Conclusions}

Nowadays, the interaction of drugs with various solvents is very important to know how their physico-chemical properties play an important role in using drugs. Many researchers studied the interactions of some anti-tuberculosis drugs like rifampicin, ethambutol, pyrazinamide, isoniazid, etc., with different solvents and at different temperatures. From these studies, it has been observed that isoniazid acts as a structure maker in aqueous solutions of Dxylose, D-arabinose, glucose and sucrose, and streptomycin sulfate is also a structure maker in aqueous solutions of L-ascorbic acid and citric acid

The ion-solvent interaction of isoniazid, streptomycin sulfate was also performed by researchers by taking alcohol, glucose, arabinose/citric acid, asparagine/glutamine, and other solvents. This study has highlighted the intermolecular interactions of few anti TB drugs with some selected solvents. Still, more research should be done for the betterment of society.

\section{Funding}

This research received no external funding.

\section{Acknowledgments}

One of the authors $(\mathrm{BBN})$ is thankful to the Principal of Vikram Deb Autonomous College, Jeypore, for providing the laboratory facility.

\section{Conflicts of Interest}

The authors declare no conflict of interest.

\section{References}

1. Meretskyi, V.; Meretska, I; Redko,S. Rational Use of Drugs: the Value of Clinical Pharmacology, JMBS, 2020; 5, 313-316, https://doi.org/10.26693/jmbs05.01.313.

2. Gunnarsson, L.; Snape, J.R.; Verbruggen, B.; Owen, S.F.; Kristiansson, E.; Margiotta-Casaluci, L.; Österlund, T.; Hutchinson, K.; Leverett, D.; Marks, B.; Tyler, C.R. Pharmacology beyond the patient - The environmental risks of human drugs. Environ. Int. 2019, 129, 320-332, https://doi.org/10.1016/j.envint.2019.04.075.

3. Dunne, S.; Shannon, B.; Dunne, C.; Cullen, W. A review of the differences and similarities between generic drugs and their originator counterparts, including economic benefits associated with usage of generic 
medicines, using Ireland as a case study. BMC Pharmacology and Toxicology 2013, 14, 1, https://doi.org/10.1186/2050-6511-14-1.

4. Mayer, A.M.S.; Guerrero, A.J.; Rodríguez, A.D.; Taglialatela-Scafati, O.; Nakamura, F.; Fusetani, N. Marine Pharmacology in 2014-2015: Marine Compounds with Antibacterial, Antidiabetic, Antifungal, AntiInflammatory, Antiprotozoal, Antituberculosis, Antiviral, and Anthelmintic Activities; Affecting the Immune and Nervous Systems, and Other Miscellaneous Mechanisms of Action. Mar. Drugs 2020, 18, https://doi.org/10.3390/md18010005.

5. Sanders, J.M.; Monogue, M.L.; Jodlowski, T.Z.; Cutrell, J.B. Pharmacologic Treatments for Coronavirus Disease $2019 \quad$ (COVID-19): A Review. JAMA 2020, 323, $1824-1836$, https://doi.org/10.1001/jama.2020.6019.

6. vonGunten, S. The Future of Pharmacology: Towards More Personalized Pharmacotherapy and Reverse Translational Research. Pharmacology 2020, 105, 1-3, https://doi.org/10.1159/000505216.

7. Gackowski, M.; Koba, M.; Pluskota, R.; Daghir-Wojtkowiak, E.; Szatkowska-Wandas, P.; Kruszewski, S. Pharmacological classification of anticancer drugs applying chromatographic retention data and chemometric analysis. Chemical Papers 2021, 75, 265-278,https://doi.org/10.1007/s11696-020-01301-3.

8. Sarkar, A.; Rahaman, H.; Singha,,U.K.; Sinha, B. Solute-solute and Solute-solvent Interactions of Paracetamol in Aqueous Solutions of $\beta$-cyclodextrin at Different Temperatures: A Volumetric and Viscometric Approach. Indian Journal of Advances in Chemical Science. 2017, 5, 230-244, https://doi.org/10.22607/IJACS.2017.504003.

9. Krakowiak, J. Apparent molar volumes and compressibilities of tetrabutyl-ammonium bromide in organic solvents. The Journal of Chemical Thermodynamics 2011, 43, 882-894, https://doi.org/10.1016/j.jct.2011.01.005.

10. Chakraborty S, Rhee KY. Tuberculosis Drug Development: History and Evolution of the Mechanism-Based Paradigm. Cold Spring Harb Perspect Med. 2015, 5, a021147. https://doi.org/10.1101/cshperspect.a021147.

11. Brown Jr. E G, Dooley. E. G, Chapman.R, Tuberculosis Drug Information Guide, 2nd edition, Curry International Tuberculosis Center and California Department of Public Health, 2012, 37-38.

12. Zhang, Y., Shi, W., Zhang, W., Mitchison, D. Mechanisms of Pyrazinamide Action and Resistance. Microbiology Spectrum, 2014, 2, 4. https://doi.org/10.1128/microbiolspec.mgm2-0023-2013.

13. Krause, K. M., Serio, A. W., Kane, T. R., \& Connolly, L. E. Aminoglycosides: An Overview. Cold Spring Harbor Perspectives in Medicine, 2016, 6, a027029, https://doi.org/10.1101/cshperspect.a027029.

14. Hayakawa, D.; Sawada, N.; Watanabe, Y.; Gouda, H. A molecular interaction field describing nonconventional intermolecular interactions and its application to protein-ligand interaction prediction. $J$. Mol. Graphics Model. 2020, 96, 107515, https://doi.org/10.1016/j.jmgm.2019.107515.

15. Raffaini, G.; Ganazzoli, F. Understanding Surface Interaction and Inclusion Complexes between Piroxicam and Native or Crosslinked $\beta$-Cyclodextrins: The Role of Drug Concentration. Molecules 2020, 25, https://doi.org/10.3390/molecules25122848.

16. Pellegrino, S.; Meyer, M.; Könst, Z.A.; Holm, M.; Voora, V.K.; Kashinskaya, D.; Zanette, C.; Mobley, D.L.; Yusupova, G.; Vanderwal, C.D.; Blanchard, S.C.; Yusupov, M. Understanding the role of intermolecular interactions between lissoclimides and the eukaryotic ribosome. Nucleic Acids Res. 2019, 47, 3223-3232, https://doi.org/10.1093/nar/gkz053.

17. Abdul Rub, M. Aggregation and interfacial phenomenon of amphiphilic drug under the influence of pharmaceutical excipients (green/biocompatible gemini surfactant). PLoS One 2019, 14, e0211077,https://doi.org/10.1371/journal.pone.0211077.

18. Kamel, M.; Morsali, A.;Raissi, H.; Mohammadifard, K. Theoretical insights into the intermolecular and mechanisms of covalent interaction of Flutamide drug with $\mathrm{COOH}$ and $\mathrm{COCl}$ functionalized carbon nanotubes: A DFT approach. Chemical Review and Letters 2020, 3, 23-37, https://doi.org/10.22034/CRL.2020.221149.1039.

19. Scheiner, S. Versatility of the Cyano Group in Intermolecular Interactions. Molecules 2020, 25, https://doi.org/10.3390/molecules25194495.

20. Sharma, S.; Banjare, M.K.; Singh, N.; Korábečný, J.; Kuča, K.; Ghosh, K.K. Multi-spectroscopic monitoring of molecular interactions between an amino acid-functionalized ionic liquid and potential anti-Alzheimer's drugs. RSC Advances 2020, 10, 38873-38883,https://doi.org/10.1039/D0RA06323A.

21. Cui, Z.; Gao, Y.-L.; Liu, J.-X.; Dai, L.-Y.; Yuan, S.-S. L2,1-GRMF: an improved graph regularized matrix factorization method to predict drug-target interactions. BMC Bioinformatics 2019, 20, 287 , https://doi.org/10.1186/s12859-019-2768-7. 
22. Adewumi, A.T.; Soremekun, O.S.; Ajadi, M.B.; Soliman, M.E.S. Thompson loop: opportunities for antitubercular drug design by targeting the weak spot in demethylmenaquinone methyltransferase protein. RSC Advances 2020, 10, 23466-23483, https://doi.org/10.1039/D0RA03206A.

23. Raj, S.; Sasidharan, S.; Dubey, V.K.; Saudagar, P. Identification of lead molecules against potential drug target protein MAPK4 from L. donovani: An in-silico approach using docking, molecular dynamics and binding free energy calculation. PLoS One 2019, 14, e0221331, https://doi.org/10.1371/journal.pone.0221331.

24. Pinzi, L.; Rastelli, G. Molecular Docking: Shifting Paradigms in Drug Discovery. Int. J. Mol. Sci. 2019, 20, https://doi.org/10.3390/ijms20184331.

25. Brahman, D.; Sinha, B. Partial Molar Volumes and Viscosity B-Coefficients of N,N'-Ethylenebis(salicylideneiminato)cobalt(II) in Binary Mixtures of 1,4-Dioxane + Methanol at $\mathrm{T}=(298.15,303.15$, 308.15, and 313.15) K. J. Chem. Eng. Data 2011, 56, 3073-3082, https://doi.org/10.1021/je200145r.

26. Brahman, D.; Sinha, B. Partial molar volumes and viscosity B-coefficients for N,N/-ethylenebis(salicylideneiminato)-diaquochromium(III) chloride in methanolic solutions of 1-butyl-2,3dimethylimidazolium tetrafluoroborate at $\mathrm{T}=(298.15,308.15$, and 318.15)K. The Journal of Chemical Thermodynamics 2014, 68, 260-269, https://doi.org/10.1016/j.jct.2013.09.018.

27. Sailaja, M.; Sarangi, D.; Dalai, B.; Mohapatra, P.; Nanda, B.B. Effect of presence of tetra alkyl ammonium bromides on solution behavior of 1-Butyl-2, 3-dimethylimidazolium chloride at different temperatures: Volumetric and acoustic studies. Chemical Data Collections 2020, 28, 100438,https://doi.org/10.1016/j.cdc.2020.100438.

28. Masson, D.O. XXVIII. Solute molecular volumes in relation to solvation and ionization. The London, Edinburgh, and Dublin Philosophical Magazine and Journal of Science 1929, 8, 218235,https://doi.org/10.12691/pmc-1-1-1.

29. Hepler, L.G. Thermal expansion and structure in water and aqueous solutions. Can. J. Chem. 1969, 47, 46134617, https://doi.org/10.1139/v69-762.

30. Ankita; Nain, A.K. Study on the interactions of drug isoniazid in aqueous-D-xylose/L-arabinose solutions at different temperatures using volumetric, acoustic and viscometric approaches. J. Mol. Liq. 2020, 298, 112086, https://doi.org/10.1016/j.molliq.2019.112086.

31. Ankita; Nain, A.K. Volumetric, acoustic and viscometric studies of solute-solute and solute-solvent interactions of isoniazid in aqueous-glucose/sucrose solutions at temperatures from $293.15 \mathrm{~K}$ to $318.15 \mathrm{~K}$. The Journal of Chemical Thermodynamics 2019, 133, 123-134, https://doi.org/10.1016/j.jct.2019.01.024.

32. Malladi, L.; Tangde, V.M.; Dhondge, S.S.; Sheikh, N. Solvation thermodynamics of anti-tuberculosis Isoniazid in aqueous and in aqueous electrolytic media. The Journal of Chemical Thermodynamics 2018, 123, 128-139, https://doi.org/10.1016/j.jct.2018.04.003.

33. Gupta, J.; Nain, A.K. Physicochemical study of solute-solute and solute-solvent interactions of homologous series of $\alpha$-amino acids in aqueous-isoniazid solutions at temperatures from 293.15 to 318.15 K. J. Mol. Liq. 2019, 278, 262-278, https://doi.org/10.1016/j.molliq.2019.01.036.

34. Gupta, J.; Nain, A.K. Study of solute-solute and solute-solvent interactions of streptomycin sulphate in aqueous-l-asparagine/l-glutamine solutions at different temperatures by using physicochemical methods. $J$. Mol. Liq. 2018, 249, 666-676, https://doi.org/10.1016/j.molliq.2017.11.063.

35. Sharma, T.; Kumar, A.; Shah, S.S.; Bamezai, R.K. Analysis of interactions between streptomycin sulphate and aqueous food acids (L-ascorbic acid and citric acid): Physico-chemical and spectroscopic insights. The Journal of Chemical Thermodynamics 2020, 151, 106207, https://doi.org/10.1016/j.jct.2020.106207.

36. Markarian, S.A.; Gabrielyan, L.S. Dielectric relaxation study of diethylsulfoxide/water mixtures. Phys. Chem. Liq. 2009, 47, 311-321, https://doi.org/10.1080/00319100701824314.

37. Stubbs, J.M.; Drake-Wilhelm, D.D.; Siepmann, J.I. Partial Molar Volume and Solvation Structure of Naphthalene in Supercritical Carbon Dioxide: A Monte Carlo Simulation Study. The Journal of Physical Chemistry B 2005, 109, 19885-19892, https://doi.org/10.1021/jp0502656.

38. Bahadur, I.; Deenadayalu, N.; Ramjugernath, D. Efects of temperature and concentration on interactions inmethanol + ethyl acetate and ethanol + methyl acetate or ethyl acetate systems: insights from apparent molar volume and apparent molarisentropic compressibility study. Thermochim. Acta. 2014, 577, 87-94, https://doi.org/10.1016/j.tca.2013.12.016.

39. Omar, Q. M., Jaubert, J. N., Awan, J. A. Densities, apparent molar volume, expansivities, Hepler's constant, and isobaric thermal expansion coefcients of the binary mixtures of piperazine with water, methanol, and acetone at $\mathrm{T}=293.15$ to 328.15 K. Int. J. Chem. Eng. 2018, 1-10. https://doi.org/10.1155/2018/8689534. 
40. Markarian, S.A.; Papanyan, Z.K.; Shahinyan, G.A. Volumetric, UV-Vis and FT IR Studies of Isoniazid in Diethylsulfoxide Solutions. J. Solution Chem. 2020, 49, 1094-1106, https://doi.org/10.1007/s10953-02001015-w.

41. Bayliss, N.S.; McRae, E.G. Solvent Effects in Organic Spectra: Dipole Forces and the Franck-Condon Principle. The Journal of Physical Chemistry 1954, 58, 1002-1006,https://doi.org/10.1021/j150521a017.

42. Nadejde, C.; Creanga, D.E.; Humelnicu, I.; Filip, E.; Dorohoi, D.O. Study on the intermolecular interactions in rifampicin ternary solutions - Calculation of microscopic parameters of rifampicin molecules. J. Mol. Liq. 2009, 150, 51-55,https://doi.org/10.1016/j.molliq.2009.09.012.

43. Deosarkar, S.D.; Ban, A.R.; Sawale, R.T.; Padghan, S.D.; Pawar, A.J.; Kalyankar, T.M. Volumetric, viscometric and refractometric behavior of glycine+\{aqueous isoniazid \} ternary mixtures at $298.15 \mathrm{~K}$ : A drug-amino acid interactions study. J. Chem. Pharm. Res. 2014, 6, 390-394.

44. Markarian, S.A.; Evangelopoulos, D.; Harutyunyan, L.R.; Pepoyan, E.K.; Guzman, J.D.; McHugh, T.D.; Bhakta, S. The Properties of Solutions of Isoniazid in Water and Dimethylsulfoxide. J. Solution Chem. 2012, 41, 1462-1476,https://doi.org/10.1007/s10953-012-9883-7. 